\title{
Comparative Effects of Two Modes of Computer-Assisted Instructional Package on Solid Geometry Achievement
}

\author{
Isiaka Amosa Gambari, Victoria Ifeoma Ezenwa, \& Romanus Chogozie Anyanwu \\ Federal University of Technology, Nigeria
}

\begin{abstract}
The study examined the effects of two modes of computer-assisted instructional package on solid geometry achievement amongst senior secondary school students in Minna, Niger State, Nigeria. Also, the influence of gender on the performance of students exposed to CAI(AT) and CAI(AN) packages were examined. This study adopted a pretest-posttest experimental design with $3 \times 2$ factorial design and a sample of 120 Senior Secondary class Two (SSII) students (60 male and 60 female). Computer-Assisted Instructional package of two modes; Animation with Text (AT), and Animation with Narration (AN) were employed as treatment instruments and a Solid Geometry Achievement Test (SGAT) was used as test instrument. A trial test was carried out and a reliability coefficient of 0.78 was obtained using the KR-21. Analysis of Variance (ANOVA) and t-test was used in analysing data collected. The study revealed that, there were significant differences in the post-test mean scores of CAI(AT), CAI(AN) and the control group $(F=11.468, \mathrm{df}=119, \mathrm{p}<0.05)$ and the Scheffe's post-hoc test revealed a significant difference between CAI(AN) and the lecture method groups, favoring $\mathrm{CAI}(\mathrm{AN})$, there was no statistically significant difference in the post-test mean scores of male and female students taught using $\operatorname{CAl}(A T)(t=0,660, d f=38, p>0.05)$ and $\operatorname{CAl}(A N)(t=1.455, d f=$ $38, p>0.05)$. Based on these findings, it was therefore recommended that mathematics teachers should be encouraged to use CAI(AN) for meaningful and effective teaching and learning of mathematics.
\end{abstract}

Keywords: Computer-assisted instruction; Multimedia-based learning; Animation+Narration; Animation+On-screen text; Solid geometry; Secondary students

\section{Introduction}

Mathematics as a subject can be seen in all facets of life and in day-to-day occupations such as internet technology, banking, construction, medicine, scientific discoveries and even in our planning of daily activities and many others. Mathematics remains a core subject in both the primary and secondary schools (FRN, 2008). Without a credit pass in mathematics at the senior secondary school level, no student can access the tertiary education in Nigeria. One of the reasons for the review of the National Policy on Education 1998 was to expand the National Mathematical Centre (NMC) whose role is to enhance mathematics teaching and learning through research (FRN, 2008). The Joint Admission and Matriculation Board (JAMB) brochure 2010 indicated that $80 \%$ of universities in Nigeria had a Mathematics department in the form of pure mathematics, industrial mathematics, mathematics/computer science, mathematics/statistics or mathematics/physics. A 
survey report also shows that all 100level students in every university that offer science, engineering and technology courses, take mathematics as a general course.

All these measures point to the importance of mathematics in the development of the nation. In spite of the importance attached to mathematics as a core subject in Nigerian schools today and its application in everyday life, there has been consistent poor performance at all levels starting from the primary school level (Agwagah, 1997; Gambari \& Adeghenro, 2008; lji \& Harbor-Peters, 2005; WAEC \& NECO May/June \& Nov/Dec., 2007-2011).

The West African Examinations Council (WAEC, 2007, 2008, 2009, 2010 \& 2011) Chief Examiners reports highlighted areas of students' weaknesses to include (i) inability to carry out simplifications of surds and indices,(ii) applications of laws of logarithm,(iii) inability in choosing appropriate scales in plotting graphs(iv) poor knowledge on the rubrics of construction, and (v) confusion on plane and solid shapes.

The problem and difficulties experienced by secondary school students in geometry has been traced to inadequate knowledge of the rubrics of construction, measurement and identification of plane shapes from the solid shapes (WAEC chief examiners report 2007; 2008; 2009; 2010; and 2011). This worrisome trend has led many researchers to search for solution(s) to poor performance in mathematics among senior secondary school students. Many researches point to the abstract nature of mathematics in classroom teaching as one of the causes of poor performance in mathematics (Bolaji, 2002; Emuhohwo, 2009; Mohammed \& Abba, 2006; Nwagbo, 2005; Zakariyya, 2008)

According to the National Council of Teachers of Mathematics (NCTM, 2008), technology is an essential tool for learning mathematics in the 21st century, and all schools must ensure that their students have access to technological innovations such as Instructional televisions, computers and other multimedia technologies. Efficient teaching maximizes the potential of multimedia technology to develop students' understanding, stimulate their interest, and increase their proficiency in mathematics.

Computer-Assisted Instruction is one of the multimedia instructions that has been empirically proved to enhance students' performance, arouse their interest, and reduce the boring and abstract nature of mathematics (Adegoke, 2010; Gambari, 2010; Kuti, 2006; Mahmood, 2002). In recent times, emphasis has shifted from the use of computer for administration, management and other uses to computer as a medium of instruction. Computers as an instructional media can come in different forms, computer based instruction (CBI), computer based learning (CBL), computer enhanced learning (CEL), computer aided learning (CAL), computer aided instruction (CAI) and computer assisted instruction(CAI). Computer Assisted Instruction (CAI) has been reported to be one of the most effective instructional strategies for developing interest, positive attitude, promoting retention ability of the students and improving the achievements of students (Gambari \& Adeghenro, 2008; Osemmwinyen, 2009; Yusuf \& Afolabi, 2010). The theories behind this success story were propounded by Paivio (1986) and Mayer (2001).

The Dual Code theory (DCT) by Paivio (1986) and the multimedia learning theory by Mayer (2001) provide theoretical support for the use of verbal and nonverbal influences on the memory. Mayer 
and his colleagues propounded principles of multimedia learning which include: (a) the coherence principle - students learn better when extraneous words, pictures and sounds are excluded rather than included, (b) the modality principle - students learn better from animation and narration than from animation and on screen text, (c) the redundancy principle - students learn better from animation, onscreen text and narration.

Computer-assisted instruction (CAI) is one of the many instructional strategies that has proved effective in integrating different types of media and bringing out a better learning outcome. Among these include, animation with text (AT), animation with narration (AN) and text with narration (TN). All these integration have shown a greater learning achievement in mathematics. Although so many researches for redundancy principle (Moreno \& Mayer, 2000); for modality principle (Taber, Martens and VanMerrieboer, 2004), the findings of some other authors were not in agreement with the redundancy principle (Ozdemir, 2009; Thalheimer, 2004). These principles support the use of different modes of CAl, Animation with text, Animation with Narration, Text with Narration and many others. The question is amongst the different modes of CAl, which modes can be more effective in instruction.

Empirical evidences on the use of different modes of CAI are inconclusive. For instance, on narration with text (NA) mode, Mayrath (2009) found that students who received the voice-only (narration) tutorial performed significantly better on the transfer test than students who received the text-only tutorial. However, Koroghlanian and Carol (2000) found that participants in the Text treatments achieved the same as participants in the Audio (narration) treatments on both the practice and post-test. Similarly on Animation with text (AT) mode, Yen, Lee and Chen (2012) reported that the group using image-based (animation) concept mapping showed higher level than the text-based group in the dimension of understanding and creating. Similarly, Mahmood (2002) revealed that CAl involving Animation with Text (AT) and Animation with Narration (AN) improves students' achievement in mathematics. However, Jolly (2003) reported no significant differences in the performance level of the students in animation-with text as compared to graphics-with-text when exposed to Life Cycle of a Monarch Butterfly in biology.

Gender equality has been a conflicting issue in mathematics achievement. Aguele and Agwagah, (2007) observed that gender disparity in enrolment STME and achievement in higher education is invariably rooted from inequality at the primary and secondary levels where the real sorting out of University bound students take place. Empirical evidences on gender in mathematics achievement have been a controversy. For instance, Gambari and Adegbenro (2008), Osemmwinyen (2009) and Yusuf (2006) found no significant difference between male and female students' achievements and retention when taught geometry, trigonometry and statistics using computer-assisted instruction. However, Kurumeh (2004) reported that female students achieved higher than male students on effects of ethno-mathematics approach and interest in geometry and mensuration, while, Kolawole (2007) found that male students achieved significantly better than female students in science education.

Little is known about the use of computer-assisted instructional package in the Nigerian education system particularly in different mode settings. In addition, very few empirical studies exist in Nigeria regarding the use of CAI in mathematics. Thus, many remain to be empirically studied on the effect of CAI modes in mathematics education, in Nigeria. Therefore this study examined the 
effects of CAI in Animation with text (AT) and Animation with narration (AN) on student's solid geometry achievement.

\section{Research Questions}

This study sought answers to the following research questions:

1) Are there differences in the post-test mean score of students taught solid geometry using CAl, animation with Text (AT), Animation with Narration (AN) and lecture method?

2) What is the difference in the post-test mean score of male and female students taught solid geometry using Animation with Text (AT)?

3) Is there any difference in the post-test mean score of male and female students taught solid geometry using Animation with Narration (AN)?

\section{Research Hypotheses}

The following null hypotheses were formulated:

1) There are no significant differences in the post-test mean scores of students taught solid geometry using, Animation with text (AT), Animation with narration (AN) and lecture method.

2) There is no significant difference in the post-test mean scores of male and female students taught solid geometry using animation with text (AT).

3) There is no significant difference in the post-test mean scores of male and female students taught solid geometry using animation with narration (AN).

\section{Methodology}

\section{Research Design}

This study adopted a pre-test, post-test experimental control group design. The two experimental groups(AT \& AN) and one control group(lecture method) were administered a pre-test before treatment and post-test after treatment. The experimental group 1 was subjected to treatment using Animation with Text (AT), the experimental group2 was subjected to treatment using Animation with Narration (AN) and the control group was taught using lecture method.

\section{Sampling and Sampling Techniques}

The sample consists of 120 senior secondary class two (SSII) students (60 male and 60 female). Based on the nature of this research, a three stage sampling technique was employed in selecting the sample. Firstly a purposive sampling technique was employed in selecting the three senior 
secondary schools based on school type (public school), facility (schoolNet), school location (Minna metropolis) and gender composition (male and female). Secondly, a simple random sampling technique was used to assign the three selected schools to two experimental and one control group. Thirdly, one arm of SSII classes in each of the school was randomly selected and finally, stratified sampling was used to select 20 male and 20 female students for the experiment.

\section{Research Instruments}

The research instruments consist of two treatments and one testing instruments. The instruments covered topics in solid geometry that include: surface area, total surface area and volumes of cubes and cuboids, curved surface area, total surface area and volume of cone, cylinder, sphere, hemisphere and pyramids.

Treatment Instrument: The treatment instruments were developed by the researchers and programmers using suitable programming languages such as micro-media flash, dream-weaver, fireworks 8 , flash 8 and MS office software in bringing out the animation showing the formation of the different shapes in a way that the students will see the major properties of these shapes. Both the treatments consist of animation of the major concepts in solid geometry and on-screen texts with lesson objectives, examples, illustrations in animation format, quizzes to be answered before navigating to the next topic. The only difference between the treatments was the addition of onscreen text $(\mathrm{T})$ in the first treatment and narration $(\mathrm{N})$ in the second treatment.

Test Instrument: The test instrument used for this study is the Solid Geometry Achievement Test (SGAT). The SGAT consists of 30-item multiple choice objective type adopted from the past Senior Secondary School Certificate Examinations (SSSCE) of West African Examinations Council (WAEC) and the National Examinations Council (NECO) questions (from 2001 - 2011). 10 out of the 30 questions tested students' ability to recall what they have learnt while 20 questions tested students' ability to apply what they have learnt to solve problems. The options are lettered A-D with each correct option carrying 1 mark and incorrect option having 0 . The scores were later converted to percentage. Although the questions have already gone through validation as they are WAEC and NECO past questions, a team of two science education and three mathematics teachers also looked at the SGAT and their suggestions and recommendations were used to modify the instrument. The administration of SGAT took 45minutes.

\section{Experimental Procedures}

Pre-test was administered to three groups, followed by six weeks treatment on the two experimental groups (AT) and (AN) and at the same time teaching the control group with lecture method.

Experimental Group I: Animation + Narration (AN): The students in this group were exposed to computers which displayed animations depicting the explanations of the concepts of geometry along with concurrent teacher-narration voice. 
Experimental Group II: Animation + On-Screen text (AT): The students in this group were exposed to computer which displayed animations depicting concepts of geometry with concurrent presentation of on-screen text. To reduce cognitive load, the corresponding words and graphics animation were presented near each other on the page.

Control Group: Lecture Method: The control group was exposed to lecture method. The researcher presented the subject matter using charts as instructional materials to explain the concept of geometry. The students listen to the lecture and copy the note on the chalkboard. Questions were entertained at the end of the lesson after which assignment were given.

Post-test was administered immediately after the treatment. Data obtained from post-test were subjected to data analysis using Analysis of variance (ANOVA), t-test and Scheffe's post-hoc test.

\section{Results}

To test for the hypotheses, the data were analyzed using t-test, one-way ANOVA and Scheffe's test using Statistical Package for Social Sciences (SPSS) version 16 at 0.05 alpha level. The results are presented based on the research hypotheses.

Table 1. ANOVA Comparison of Mean Achievement Scores of Experimental and Control Groups at Pre-test

\begin{tabular}{lrrrrr}
\hline Source & SS & df & MS & F & Sig $(p)$ \\
\hline Between Group & 466.127 & 2 & 233.064 & & \\
Within Group & 17536.93 & 117 & 149.888 & $1.555^{\text {ns }}$ & 0.216 \\
Total & 18003.06 & 119 & & & \\
\hline
\end{tabular}

ns: not significant at the 0.05 level.

From Table 1, the F-value of 1.555 was not significant at the 0.05 level. This indicates that there are no statistically significant differences among the performance of students taught with Animation + on-screen Text (AT), Animation + Narration (AN) and control group $(\mathrm{F}=1.555, \mathrm{df}=$ $117, p=0.216)$. This implies that there are no significant differences among sample students before the commencement of the experiment. This means the students are comparable.

\section{Hypothesis One}

There is no significant difference in the post-test mean scores of students taught solid geometry using CAl, animation with text (AT), animation with narration (AN) and lecture method.

In order to test this hypothesis, ANOVA was used to analyze the mean scores. The summary of this analysis is shown on table 2 . 
Table 2. ANOVA Comparison of Mean Achievement Scores of Experimental and Control Groups at Post-test

\begin{tabular}{lrrrrr}
\hline Source & SS & df & MS & F & Sig $(p)$ \\
\hline Between Group & 5360.949 & 2 & 2680.474 & & \\
Within Group & 2734623 & 117 & 233.728 & 11.468 & $0.000^{*}$ \\
Total & 32707.18 & 119 & & & \\
\hline
\end{tabular}

*: significant at the 0.05 level.

From Table 2, the calculated F-value of 11.468 was not significant at the 0.05 level. This indicates that there is statistically significant difference among the performance of students taught with animation + on-screen text (AT), animation + narration $(N)$ and control group $(f=11.468, d f=117$, $\mathrm{p}=0.000$ ). Hence, $\mathrm{Ho}_{1}$ was rejected. Therefore, there are significant differences among students taught mathematics with AT, AN packages and lecture method. Scheffe's post-hoc analysis was further carried out to determine the direction of differences. The analysis of post-hoc is shown in Table 3.

Table 3. Summary of Scheffe's Post-hoc Analysis of the Mean Achievement Scores of Experimental and Control Groups

\begin{tabular}{lllll}
\hline Groups & Means & Group I (AT) & Group II (AN) & Group III (cont) \\
\hline Group I (AT) & 65.38 & & 0.052 & 0.071 \\
Group II (AN) & 73.80 & 0.052 & & $0.000^{*}$ \\
Group III (Cont) & 54.43 & 0.071 & $0.000^{*}$ & \\
\hline
\end{tabular}

* The mean is significant at the 0.05 level.

The result in Table 3 indicates that there was no significant difference in the mean achievement scores of students exposed to AT $(X=65.38)$ and those exposed to AN $(X=73.80)$. It also indicates no significant difference in the mean achievement scores of students exposed to AT $(X=65.38)$ and those exposed to lecture method (54.43). Significant difference was established in the mean achievement scores of students exposed to AN $(X=73.80)$ and those exposed to lecture method $(X$ =54.43).

\section{Hypothesis Two}

There is no significant difference on the post-test mean scores of male and female students taught using animation with text (AT). 
In order to test this hypothesis, t-test statistics was used to analyze the mean scores. The summary of this analysis is shown on table 4.

Table 4. t-test Analysis on Achievement Scores of Male and Female Students in AT Group

\begin{tabular}{lrrrrrr}
\hline Gender & $\mathrm{N}$ & $\mathrm{df}$ & Mean & SD & t-value & $\mathrm{p}$ - value \\
\hline Male & 20 & & 64.465 & 17.216 & & \\
& & & & & & \\
& & 38 & & & $0.660^{\text {ns }}$ & 0.513 \\
Female & 20 & & 67.300 & 8.492 & & \\
\hline
\end{tabular}

ns= not significant at .05 level.

Table 4 presents the t-test of male and female students of experimental group I (AT). The mean scores of the male students were 64.465 and 67.300 for the female students. The t-value of 0.660 was not significant at the 0.05 level. This indicates that there is statistically no significant difference between the male and female students taught with CAI with $A T,(t=0.660, d f=38, p$ $=0.513)$. Hence, $\mathrm{Ho}_{2}$ was upheld. Therefore, there is no significant difference between male and female students taught with animation with text package.

\section{Hypothesis Three}

There is no significant difference on the post-test mean scores of male and female students taught using animation with narration (AN).

In order to test this hypothesis, t-test statistics was used to analyze the mean scores. The summary of this analysis is shown on table 5.

Table5. t-test Analysis on Mean Achievement Scores of Males and Females in AN Group

\begin{tabular}{llccccc}
\hline Variable & $\mathrm{N}$ & $\mathrm{df}$ & Mean & SD & t - value & $\mathrm{p}$ - value \\
\hline Male & 20 & & 70.300 & 14.940 & & \\
& & 38 & & & $1.455^{\mathrm{ns}}$ & 0.154 \\
& & & & & \\
Female & 20 & & 76.965 & 14.020 & & \\
\hline
\end{tabular}

ns= not significant at .05 level

Table 5 presents the t-test of male and female students of experimental group II (AN). The mean scores of the male students were 70.300 and 76.965 for the female students. The t-value of 1.455 was not significant at the 0.05 level. This indicates that there is statistically no significant difference between the male and female students taught with CAI with $A N,(t=1.455, d f=38, p=$ 0.154). Hence, $\mathrm{Ho}_{3}$ was upheld. Therefore, there is no significant difference between male and female students taught with animation with text package. 


\section{Discussion}

The results of hypothesis one reveal that there are significant differences in the learning achievements in favor of the group taught solid geometry concepts with animation with narration. This result agrees with the findings of Mayrath (2009) and Yen, Lee, and Chen (2012) who reported that students taught with animation with narration performed significantly better than those in control group. The result of this study validates the findings Richard Mayer's (2001) multimedia modality principle. Also the result confirmed the findings of Taber, Martens and VanMerrieboer (2004) and Adegoke (2010) that multimedia based instruction involving animation with narration results in a more significant learning outcome than animation with onscreen text. It agrees with the findings of Mahmood (2002) which revealed that CAl involving Animation with Text (AT) and Animation with Narration (AN) improves students' achievement in mathematics.

The results of hypothesis two and three show that there is no significant difference between male and female students taught solid geometry concepts with Animation with Text (AT) and those in Animation with Narration (NA). This finding is in agreement with the results of Gambari and Adegbenro (2008) Osemmwinyen (2009) and Yusuf (2006) who found no significant difference between male and female students' achievement and retention when taught geometry, trigonometry and statistics using computer-assisted instruction. However, this result contradicts the findings of Kurumeh (2004) which reported that female students achieved higher than male students on effects of ethno-mathematics approach and interest in geometry and mensuration, while, Croxford (2002) reported that male students achieved significantly better than female students in science education.

\section{Conclusion and Recommendations}

This study has shown that integrating animation with text and animation with narration in a computer based multimedia learning environment enhanced students' learning outcome in mathematics. Computer assisted instructional packages involving animation with narration (AN) generates more learning outcome than animation with on screen text (AT). The use of CAI packages that involve animation with narration (AN) and animation with text (AT) can serve as a medium of reducing students' low achievements in mathematics and is also gender friendly.

Based on the findings of this study, it is recommended that the researchers' developed Animation with Narration package which was found to be effective for teaching solid geometry among senior secondary school students should be encouraged in the teaching of mathematics. To achieve this, mathematics teachers should be trained on the effective use of computer-based multimedia instruction through seminars, workshops and conferences.

\section{References}

Adegoke, B. A. (2010). Integrating animation, narratives and textual information for improving physics learning. Electronic Journal of Research on Educational Psychology, 8(2), 725-748. 
Aguele, L. I. \& Agwagah, N. U. V. (2007).Female participation in science, technology and mathematics (STM) education in Nigeria and national development. Journal of Social Science, 15(2), 121-126.

Agwagah, N.U.V. (1997). Mathematics reading in improving mathematics learning and achievement. ABACUSS, 24(1), 112-116

Bolaji, C. (2002). Mathematics achievement: Fear of success among senior secondary school students in Kaduna. University of Ado-Ekiti Journal of Education (UNADJOE) 1(2), 16-32.,

Emuhohwo, U.M. (2009). Science and technology education and the millennium development goals (MDGs). The Voice of Teachers, 1(2), 128-132.

Federal Republic of Nigeria (2008). National policy on education. Lagos: NERDC

Gambari, A. I. \& Adeghenro, D. V. (2008). Effects of computer assisted instruction on mathematics achievement amongst students in Minna Metropolis. Ilorin Journal of Education, 27, 63-70.

Gambari, A. I. (2010). Effects of computer supported cooperative learning strategy on the performance of senior secondary students in physics in Minna, Nigeria (Unpublished doctoral dissertation). University of Ilorin, llorin.

Iji, C. O. \& Harbor-Peters, A. (2005). Effects of logo and basic programs on the achievement in geometry of junior secondary school students. ABACCUS, 30(1), 67-77

Jolly, S. (2003). Studying the effectiveness of animation and graphics with text on fourth, fifth and sixth graders (Unpublished master's thesis). University of Nebraska.

Kolawole, E. B. (2007). Effects of competitive and cooperative learning strategies on academic performance of Nigerian students in mathematics. Educational Research Review, 3(1), 3337.

Kurumeh, M. S. C. (2004). Effect of ethno-mathematics teaching approach on students achievement and interest in geometry and mensuration (Unpublished doctoral dissertation). University of Nigeria Nsukka.

Kuti, J. B. (2006). Effects of multimedia instructional strategy on senior secondary students learning outcome in physics in Ogun state, Nigeria (Unpublished M.Ed. project). University of Ibadan, Ibadan.

Mahmood, S. J. (2002). Enhancing the mathematics achievement of college bound students, combining computer animation with text and narration. U.S. Department of Education, Office of Educational Research and Improvement, Educational Research and Resource Center. Retrieved on 06 February 2012 from www.Ericdigest.com

Mayer, R. E. (2001). Multimedia learning. Cambridge: Cambridge University Press.

Mayrath, M. C. (2009). Examining factors that affect performance in complex simulation environments (Unpublished doctoral dissertation). The University of Texas at Austin.

Mohammed, A. \& Abba, H. (2006). Retooling science teacher education for special needs education and national development. A paper presented at the $6^{\text {th }}$ National Conference of NCCE. Jibril Aminu Hall, Federal College of Education, Yola. 
Moreno, R. \& Mayer, R. E. (2000). A coherence effects in multimedia learning. The case of minimizing irrelevant sounds in the design of multimedia instructional messages. Journal of Educational Psychology, 97, 117-125.

Nwagbo, C. R. (2005). Attachment of professionalism on science education conferences and skills needed by science teacher. Proceedings of the $46^{\text {th }}$ Annual Conference of STAN. Ibadan: Heinemann Books.

NCTM (2008). The role of technology in the teaching and learning of mathematics: A position of the National Council of Teachers of Mathematics. Retrieved on 07 March 2012 from http://www.nctm.org.com

Osemwinyen, A. C. (2009). Effects of e-learning on retention and achievement in secondary school mathematics in Abuja, Nigeria (Unpublished doctoral dissertation). University of Nigeria, Nsukka.

Ozdemir, D. (2009). The effects of context dependency of seductive details on recall and transfer in a multimedia learning environment (Unpublished doctoral dissertation). Virginia Polytechnic Institute and State University, Blacksburg, Virginia.

Paivio, A. (1986). Mental representation: A dual-coding approach. Oxford, England: Oxford University Press.

Taber, H. K, Martens, R. L., \& Van Merrieboer, J. J. G. (2004).Multimedia instructions and cognitive load theory: effects of modality and cueing. British Journal of Educational Psychology, 74, 71-81.

Thalheimer, W. (2004). Bells, whistles, neons and purple prose: When interesting words, sounds and visuals hurt learning and performance; a review of the seductive-argumentation research. Retrieved on 07 March 2012 from http:www.work-learning.com/seductive_ augmentation.

WAEC (2011). Chief examiners report. Lagos: WAEC

WAEC $(2007,2008,2009,2010, \&$ 2011).Candidates enrolment statistics. Research and Statistics Unit. Lagos: WAEC.

Yen, J., Lee, C. \& Chen, I. (2012). The effects of image-based concept mapping on the learning outcome and cognitive processes of mobile learners. British Journal of Educational Technology, 43(2), 307-320.

Yusuf, F.I. (2006). Effects of using computer assisted instruction on the learning of mathematics at senior secondary school level in Minna, Niger State, Nigeria (Unpublished master's thesis). Science Education Department, Federal University of Technology Minna, Nigeria.

Zakariyya, A. (2008). An appraisal of the constructivist theory in mathematics education. Journal of Science, Technology and Mathematics Education, Special Edition. 11-14.

Correspondence: Isiaka Amosa Gambari, Senior Lecturer, Science Education Department, Federal University of Technology, Minna, Nigeria 